\title{
Behavioral Patterns for Automatic Detection of Learning Styles in Learning Management Systems: a Case Study
}

\author{
Guillermo Salazar Lugo ${ }^{1}$, Luis-Felipe Rodríguez ${ }^{2}$, \\ Ramona Imelda García López ${ }^{1}$, Adrián Macías Estrada ${ }^{2}$, \\ Moisés Rodríguez Echeverría ${ }^{2}$ \\ 1 Instituto Tecnológico de Sonora, Department of Education, \\ Mexico \\ ${ }^{2}$ Instituto Tecnológico de Sonora, Department of Computer and Design, \\ Mexico \\ \{gsalazar47040, luis.rodriguez, imelda.garcia, adrian.macias, \\ moises.rodriguez\}@itson.edu.mx
}

\begin{abstract}
In this paper we present advances of a case study designed to determine which student behaviors are more informative when classifying LMS's users according to their learning style. This case study represents the first step towards developing a mechanism for automatic detection of learning styles in LMS, which takes into account behavioral, affective and performance patterns. The contribution of this paper will benefit researchers and practitioners in the field of educational technology with interest in generating personalized learning environments based in LMS.
\end{abstract}

Keywords: Intelligent learning environments, behavioral patterns, automatic detection of learning styles, learning management system.

\section{Introduction}

The education model that prevails in most educational systems is characterized by a method in which the instruction is the same for all learners, without distinction of their particular learning styles and preferences [?, ?]. This traditional education model considers the professor as the main actor of the teaching-learning process, minimizing the role of the learner as an individual that only receives information [?]. Although this model guarantees and facilitates access to education for all individuals, it may hinder the development of skills and learning of most students [?].

For computer science students, the traditional education model represents an important challenge when learning algorithms [?,?,?]. The algorithms course requires students to develop analytic and problem solving skills as well as to be able to understand abstract concepts related to the design of algorithms. 
Moreover, given that 1) this course is usually offered in the first semester, 2) students may have profiles different from computer science (e.g., accounting or business administration), and 3) each student has a different pace and style of learning, the traditional model may be unsuitable for addressing these issues and helping to develop the required skills. These characteristics of the algorithm course demand a teaching-learning process designed to provide personalized instruction. However, given the multiple constraints in educational institutions (e.g., in terms of infrastructure and human resources), the number of learners that must attend a same course is large, making the generation of personalized learning environments a very complex task.

The generation of learning environments centered on the student can help to address some of the weaknesses of the traditional education model [?]. A personalized learning environment is designed to meet the learners' needs, interests, rhythms and styles. To establish a personalized learning environment, it is required the implementation of two mechanisms: 1) a mechanism to understand the situation of the student in terms of emotional and cognitive states, previous knowledge, skills, interests, response to situations related to the teachinglearning process, pace and learning style; and 2) a mechanism to generate personalized learning environments that meet the needs of learners once the mentioned characteristics are identified.

LMS have been successfully used for e-learning [?]. This type of educational platform aims at supporting teachers in creating and managing online courses and provide them with a variety of features that can be included in a course such as learning material, quizzes, discussion forums, and assignments [?,?]. LMS focuses on the presentation of educational material and is a suitable tool for generating personalized learning environments by first implementing a mechanism for automatic detection of learning styles, so that students are characterized, and then implementing a mechanism to adapt the instruction to meet such learning style. The importance of learners' behavior patterns for the automatic detection of learning styles in LMS has also increased in recent years, mainly due to the capabilities of LMS for monitoring and storing data related to the behavior of users (e.g., browsing patterns, time spent on a course, type of resources used).

In this paper we present advances of a case study designed to determine which student behaviors are more informative when classifying LMS's users according to their learning style. This case study represents the first step towards developing a mechanism for automatic detection of learning styles in LMS, which takes into account behavioral, affective and performance patterns. The contribution of this paper will benefit researchers and practitioners in the field of educational technology with interest in generating personalized learning environments based in LMS.

\section{Learning Styles and Behavior Patterns}

Learning styles describe the manner and the conditions in which learners receive, process, store and retrieve more effectively and efficiently what they are trying 
Behavioral Patterns for Automatic Detection of Learning Styles in Learning Management Systems...

to learn [?]. The literature in the field of psychology reports various models of learning styles that have been used in the automatic identification of learning styles [?]. The following list shows the categories used to classify learners in some of these models :

- The Kolb model classifies students into four categories: divergent, convergent, assimilating, and accommodating,

- The Gardner's theory of multiple intelligence defines eight types of intelligence: logical/mathematical, linguistic, spatial, musical, kinesthetic, naturalist, interpersonal and intrapersonal,

- The Felder and Silverman model proposes four dimensions with two styles each: processing (active and reflexive), perception (sensory and intuitive), input (visual, verbal) and understanding (global sequential).

Behavior patterns commonly used in the automatic identification of learning styles are classified into three groups according to the type of information used to infer styles: performance, feedback and behavior. Feldman et al. [?] describe some variables that can be monitored in learning platforms and which can be used to identify learning styles according to the categories defined in the FelderSilverman model. The following list describes some of these variables organized according to the categories of the Felder-Silverman model:

- Active: number of answered questions and number of performed exercises,

- Reflective: number of visited learning content and number of visits to a forum,

- Sensing: number of right answers given after seeing an example and number of correctly answered questions about details,

- Intuitive: number of right answers given after a theoretical explanation, number of correctly answered questions about concepts, number of correctly answered questions about developing new solutions,

- Visual: number of right answers given after seeing an image and number of images clicked,

- Verbal: number of right answers given after reading a text, number of visits to a forum,

- Sequential: number of times the student chooses to be guided through the steps of solving a problem and number of correctly answered questions about details,

- Global: number of times the student chooses to solve a problem straight away and number of visited outlines.

These variables are also useful to determine the type of user behavior that needs to be monitored in LMS in order to infer learning styles.

\section{Proposal}

We designed a case study to determine which student behaviors are more informative to classify LMS's users according to their learning style. This case 
study represents the first step towards developing a mechanism for automatic identification of learning styles. This mechanism attempts to take advantage of common features and functionality in LMS such as Moodle, without making modifications or extensions to the platform.

The case study consisted in preparing academic resources and making them available to learners using a LMS. Then, a classification tool is used for analyzing the user behavior monitored and stored by the LMS and the data obtained from applying a learning style instrument to participants. This analysis process results in the definition of behavioral patterns useful to identify user's learning styles. Figure 1 illustrates the elements included in the proposed case study and their interrelationships.

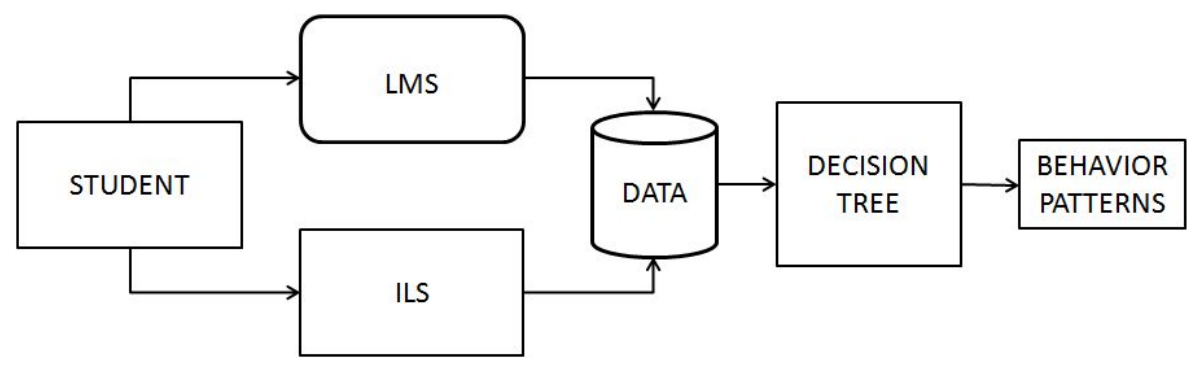

Fig. 1. Components included in the case study proposed

In the case study participated 134 students enrolled in an introductory course of computational Algorithms. This course is aimed at first semester students of Software Engineering at the Technological Institute of Sonora. All students used Moodle during five days as a support for classroom instruction. The instructional role of Moodle was to reinforce the topics reviewed each day. Moodle is an open source LMS, which allows the modification of the system to meet different needs. Moodle includes mechanisms to show information of learners in terms of number of access to resources and activities of courses, their qualifications, participation in groups, forums, chats and others. This information allows the user and professors to understand the learners' behavior within the platform. Based on these advantages of Moodle and the fact that it is highly adopted by the instructional community, this educational platform was selected as the LMS to be used in the proposed case study.

The academic resources prepared for learners are related to topics of the Algorithm course. These resources are in various formats such as lectures, videos, and presentations. Resources and Activities included in Moodle and presented to the students were used to obtain information about their behavior. Moreover, the task component was used to design exercises while the page component for designing learning content, examples, and outlines. We prepared different versions of each type of resource in terms of complexity. For example, exercises were classified as basic, medium and advanced. Moreover, each learning content 
Behavioral Patterns for Automatic Detection of Learning Styles in Learning Management Systems...

were classified in text, graphic or video. Chats and forums where also used for learners' communication and collaboration. All these features are common to most LMS, including Sakai, Claroline, and RLN.

Once students finished the course, data related to their behavior were extracted from the Moodle database and combined with the results of the ILS questionnaire to generate a consolidated database which will serve as a data source for Weka, a tool that facilitates the data analysis using well-know algorithms. In particular, we will use Weka to generate a learning decision tree in order to identify patterns of behavior that are informative to infer users' learning style.

\section{Preliminary Results}

The following list describes the steps that have been carried out according to the case study described in the previous version:

1. Setting up the LMS. Moodle was installed and configured on a server with public IP to provide access to students via the Internet. Students were provided with a user-name and password.

2. Course and Content. A new course was configured in Moodle and four modules included (one for each topic of the introductory algorithms course). The course content was composed by three basic exercises, three intermediate exercises, three advanced exercises, four assignments, four forums for discussing learners' questions and contributions, two outline pages, sixteen examples, six graphic learning content, four text learning content and three video learning content (see Figure 2).

3. Students Style Identification. Students were asked to answer the Spanish version of the Index of Learning Style (ILS) questionnaire based on the Felder-Silverman model (available online) [?]. The first day of the course, students sent the completed questionnaire and the results page generated by the site (the learning style of each student). The information of each student was then captured in the Moodle database.

4. Behavior monitoring. During five days, students used Moodle to send assignments and reinforce their knowledge on each topic using the learning contents, exercises, examples, forums and chat rooms freely without it being mandatory in any of the cases. To record the student activity, preset options of event logging in Moodle were also used.

5. Data extracting. SQL queries on tables containing information related to student behavior within the platform were generated. The SQL queries were designed to answer the following questions for each student:

- How many exercises does the student visited?

- How many exercises visited by the student are basic, intermediate and advanced?

- How many learning contents visited by the student are text, graphics and video? 
Guillermo Salazar Lugo, Luis-Felipe Rodríguez, Ramona Imelda García López, et al.

- How many times the student visited a forum?

- How many times did the student participate in a forum?

- How many times did the student visit the outlines?

- How many times did the student visit examples?

- How many times did the student visit a chat?

- How many times did the student participate in a chat?

- How many times did the student login Moodle and at what time?

6. Data analysis. Students were classified in terms of their learning style based on the score obtained in the ILS questionnaire, which considers the following categories of the Felder-Silverman model: active / reflective, sensitive / intuitive, visual / verbal, sequential / global. Participants were discarded when their learning style was balanced for all dimensions or when their scores in two or more categories were high. Students with a clear bias towards a specific style were easily classified. For example, if a student had the classification values ACT_REF=equilibrated, SEN_INT=highly intuitive, VIS_VRB=moderated visual, SEQ_GLO=moderated global, then the style assigned to this student was intuitive. However, if a student had the classification values ACT_REF=equilibrated, SEN_INT=equilibrated, VIS_VRB=moderated visual, SEQ_GLO=moderated global, then it was considered that there was not enough evidence to clearly define a learning style (in this case the data were discarded). Table 1 shows the classification criteria used for each dimension of the Felder-Silverman model.

Table 1. Classification criteria by dimension.

\begin{tabular}{llllll}
\hline Dimensions & \multicolumn{4}{c}{ Classification Values } \\
\hline ACT_REF & Highly & Moderated & Balanced & Moderated & Highly \\
& Active & Active & & Reflexive & Reflexive \\
\hline SEN_INT & Highly & Moderated & Balanced & Moderated & Highly \\
& Sensitive & Sensitive & & Intuitive & Intuitive \\
\hline VIS_VRB & Highly & Moderated & Balanced & Moderated & Highly \\
& Visual & Visual & & Verbal & Verbal \\
\hline SEQ_GLO & Highly & Moderated & Balanced & Moderated & Highly \\
& Sequential & Sequential & & Global & Global \\
\hline
\end{tabular}

From 134 students enrolled in the course, only 82 answered the ILS questionnaire and after data analysis, 55 students were correctly classified into a learning style as shown in Table 2 .

\section{Conclusions and Future Work}

In this paper we proposed a case study to determine behavioral patterns for automatic detection of Learning Styles in LMS. We presented and described the 
Behavioral Patterns for Automatic Detection of Learning Styles in Learning Management Systems...

Tópico II. Estructuras condicionales

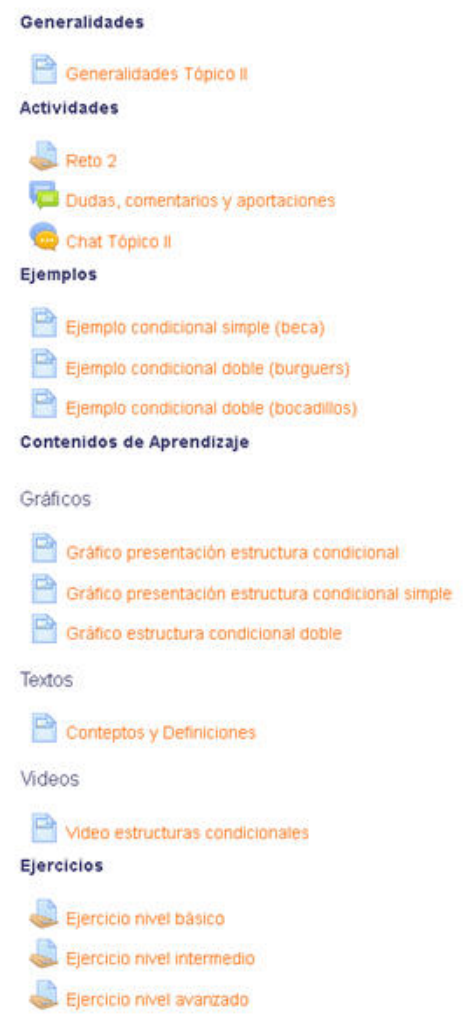

Fig. 2. Interface of the LMS including academic material

main components included in this case study as well as phases that were carried out. Preliminary data extracted from the Moodle database provide evidence for the feasibility to monitor and record data related to the behavior of students in an open license LMS without having to carry out special configurations or functionality extensions. As future work, the data generated in this preliminary work will be used as input to Weka in order to generate a learning decision tree. We attempt to employ this technique to determine which user behaviors in a LMS are more informative when classifying students according to their learning style. Once behavior patterns are associated to each learning style category, we will carry out the proposed case study but omitting the application of the ILS instrument in order to validate the results. We are also planning to monitor the dynamics of students in terms of their affective state when using the LMS. The main purpose is to understand how informative are affective aspects for the automatic identification of learning styles. 
Guillermo Salazar Lugo, Luis-Felipe Rodríguez, Ramona Imelda García López, et al.

Table 2. Learners classified according to their learning style

\begin{tabular}{lll}
\hline Learning Style & Frequency & Percentage \\
\hline Active & 12 & 22 \\
Reflexive & 6 & 11 \\
Sensitive & 5 & 9 \\
Intuitive & 5 & 9 \\
Visual & 18 & 33 \\
Verbal & 3 & 5 \\
Sequential & 3 & 5 \\
Global & 3 & 5 \\
\hline Total & $\mathbf{5 5}$ & $\mathbf{1 0 0}$ \\
\hline
\end{tabular}

Acknowledgments. This work was partially funded by the SEP-PRODEP through the project ITSON-PTC-089.

\section{References}

1. Arnove, R.F.: Comparative education and world-systems analysis. Comparative Education Review pp. 48-62 (1980)

2. Darling-Hammond, L.: Teacher learning that supports student learning. Teaching for intelligence 2, 91-100 (2008)

3. Despotović-Zrakić, M., Marković, A., Bogdanović, Z., Barać, D., Krčo, S.: Providing adaptivity in moodle lms courses. Journal of Educational Technology \& Society 15(1), 326-338 (2012)

4. Feldman, J., Monteserin, A., Amandi, A.: Automatic detection of learning styles: state of the art. Artificial Intelligence Review pp. 1-30 (2014)

5. Gomes, A., Mendes, A.J.: Learning to program-difficulties and solutions. In: International Conference on Engineering Education-ICEE. vol. 2007 (2007)

6. Graf, S., Shuk, K., Liu, T.C.: Identifying learning styles in learning management systems by using indications from students' behaviour. In: Advanced Learning Technologies, 2008. ICALT'08. Eighth IEEE International Conference on. pp. 482486. IEEE (2008)

7. Hannafin, M.J., Hill, J.R., Land, S.M.: Student-centered learning and interactive multimedia: Status, issues, and implication. Contemporary Education 68(2), 94 (1997)

8. Holzman, L.: Schools for growth: Radical alternatives to current educational models. Lawrence Erlbaum Associates Publishers (1997)

9. James, W.B., Blank, W.E.: Review and critique of available learning-style instruments for adults. New Directions for Adult and Continuing Education 1993(59), 47-57 (1993)

10. Jenkins, T.: On the difficulty of learning to program. In: Proceedings of the 3rd Annual Conference of the LTSN Centre for Information and Computer Sciences. vol. 4, pp. 53-58 (2002)

11. Llorente Cejudo, M.C.: Towards e-learning from free software. moodle like a learning managament system (lms) within reach of all. COMUNICAR (28), 197-202 (2007) 
Behavioral Patterns for Automatic Detection of Learning Styles in Learning Management Systems...

12. Moroni, N., Señas, P.: Estrategias para la enseñanza de la programación. In: I Jornadas de Educación en Informática y TICs en Argentina (2005)

13. Solomon, B.A., Felder, R.M.: Index of learning styles. Raleigh, NC: North Carolina State University. Available online (1999) 